\title{
PARATOPIA DA ESCRITORA E REORIENTAÇÃO DE SUA IMAGEM: A CONDIÇÃO DA OBSCENA SENHORA H. ${ }^{40}$
}

Rafael COSSETTI

Este trabalho está inserido em uma pesquisa maior que pretende estudar a interseção entre os discursos do campo literário na perspectiva enunciativo-discursiva da Análise do Discurso de linha francesa (AD), desenvolvida por Maingueneau (1996, 2001, 2010, 2015, 2016). Fundamentados nesse aporte teórico-metodológico, investigamos a paratopia da escritora ${ }^{41}$ na produção discur-

40 Este estudo foi realizado com o apoio da Coordenação de Aperfeiçoamento de Pessoal de Nível Superior (CAPES).

41 Embora Maingueneau (2016) utilize a expressão "paratopia do escritor", optamos por ajustá-la à figura feminina que afiança essa produção discursivo-literária. Entendemos, entretanto, que esse ajuste é falho, pois deveria ser realizado em conjunto com o levantamento das condições sócio-históricas da autoria feminina no campo literário, o que excede, por enquanto, o objetivo deste estudo. Esperamos poder realizá-lo nos próximos desdobramentos desta pesquisa, pois comprometemo-nos com a celebração da produção de escritoras e o combate à sua exclusão e ao seu apagamento do campo literário. Sobre isso, Queiroz 
sivo-literária de Hilda Hilst (1930-2004), destacando o momento em que busca responder ao silêncio da crítica e do público (HILST, 1989). Embora seja responsável por uma produção extensa em vários gêneros - são mais de 20 livros de poesia, 11 de prosa e oito peças de teatro -, em vários momentos Hilda se mostrou decepcionada com a falta de um público, conforme indica Cecilio (2018). Depois de 40 anos de dedicação a vários gêneros do campo literário, Hilda opta por um caminho menos sério (HILST, 1989). Nessa nova orientação, são produzidos quatro livros que, posteriormente, ficam conhecidos como a tetralogia obscena: três em prosa, $O$ caderno rosa de Lori Lamby e Contos descárnio - Textos grotescos, ambos publicados em 1990, Cartas de um sedutor, publicado no ano seguinte, e um em poesia, Bufólicas, publicado em 1992, mesmo ano que começa a publicar de forma assídua crônicas, gênero que não havia explorado até então. Vinculadas sobretudo às entrevistas concedidas pela autora, essas produções ajudam a delinear uma nova relação com a crítica e o público brasileiros.

No âmbito da AD, os estudos de Maingueneau (1996, 2001, $2010,2015,2016$ ) propõem uma cartografia do universo discursivo segundo as propriedades compartilhadas por determinados tipos de discursos. Ao se considerar que "todo agrupamento se faz seguindo um determinado ponto de vista e se desfaz quando o ponto de vista muda" (MAINGUENEAU, 2015, p. 140), essa proposição pode ser ajustada e refinada, à medida que outros empreendimentos analíticos são efetuados e ajudam a deslocar o ponto de vista inicial. Podem-se distinguir ${ }^{42}$, considerando o escopo deste capítulo, três segmentos do universo discursivo, categorizados de acordo

(2000) afirma que as questões de gênero ajudam a explicar, em conjunto com questões históricas, a exclusão de Hilda Hilst do cânone literário.

42 Como lembra Maingueneau (2015), a tripartição apresentada não dá conta de todo o universo discursivo. As características dos discursos político e publicitário, por exemplo, desafiam-na. 
com a relação que mantêm com a sociedade: a topia, que abarca todos os discursos que pertencem plenamente à sociedade; a atopia, que, em oposição ao anterior, concerne a práticas discursivas que se esgueiram por espaços muito restritos, e a paratopia, que se refere a um "pertencimento" impossível, a uma posição fronteiriça que faz o discurso se apresentar como conectado a uma fonte legitimadora. A paratopia conduz a investigação a partir daqui.

De acordo com essa cartografia, o discurso literário não pode se fixar em nenhum âmbito social, isto é, não é desenvolvido, administrado ou legitimado por instituições facilmente reconhecíveis, permanecendo em uma negociação paradoxal entre lugar e não lugar que alimenta o próprio ato de enunciação. Esse caráter paradoxal é característico nos discursos constituintes, como os discursos filosófico, científico, teológico ${ }^{43}$ e literário, os quais se comportam como discursos fundadores que validam a si próprios por meio de suas cenas de enunciação. A paratopia se manifesta, conforme Maingueneau (2010, 2015), em dois níveis complementares: o de cada discurso constituinte e o de cada produtor/a desse tipo de discurso.

É fundamental explicitar, desde já, que concordamos com Maingueneau $(2001,2016)$ quanto ao enlaçamento entre a produção de um/a escritor/a e os ritos que controla, a fim de mostrar a si mesma/o e ao público sinais de sua legitimidade enquanto produtor/a de um discurso constituinte. Esses ritos legítimos se relacionam, inclusive, a um posicionamento no campo literário, uma maneira de explorar e de interferir nos comportamentos con-

43 Maingueneau (2016) não diferencia o discurso religioso do discurso teológico, usando a denominação "discurso religioso", para se referir a um dos discursos constituintes. Alguns pesquisadores, como Nascimento e outros (2009), defendem a "constituência" do discurso teológico, na medida em que ele serve de base para o discurso religioso, que pode ser compreendido como profundamente institucionalizado, logo, não constituinte. 
dicionados pela instituição literária. Retornaremos a essa questão, na seção dedicada à paratopia da/o escritor/a e ao gerenciamento de sua imagem, com o intuito de diferenciar as instâncias enunciativas envolvidas nesse processo complexo que é a enunciação literária.

Nosso objetivo, em vista disso, é examinar a paratopia da escritora e a reorientação da sua imagem na fronteira entre espaço canônico e espaço associado do discurso hilstiano. Para tanto, analisamos, em conjunto, uma entrevista com a autora veiculada em 1989 no jornal Correio Popular e três crônicas da coletânea 132 crônicas: cascos \& carícias e outros escritos, publicadas pela primeira vez também no jornal campineiro entre 1992 e 1995. São elas: "Por quê, hein?", “Tamo numa boa!" e "'Esqueceram de mim' ou 'tô voltando"'. Tanto as crônicas quanto a entrevista são compreendidas aqui por uma via discursiva, o que viabiliza o apagamento da divisão texto-contexto e torna possível a analisar o discurso literário como um processo de construção de uma identidade e de sua legitimação.

O capítulo está subdividido em quatro seções. Na primeira, são discutidas as especificidades de uma pesquisa sobre a enunciação literária na disciplina da Análise do Discurso, ao mesmo tempo em que são demarcadas características basilares desse tipo de enunciação, as quais o diferenciam de outros tipos de enunciação. $\mathrm{Na}$ segunda, observam-se as noções de paratopia da/o escritor/a e de imagem de autor/a. Na terceira, realizamos a análise da entrevista e das crônicas, a fim de identificar a paratopia da escritora e a reorientação da sua imagem na relação entre os espaços canônico e associado do discurso hilstiano. A finalidade da última seção, enfim, é traçar considerações sobre o trabalho realizado e indicar outros percursos para a ampliação e o aprofundamento das pesquisas sobre o discurso literário, segundo a perspectiva enunciativo-discursiva da Análise do Discurso. 


\section{O que significa examinar a enunciação literária na Análise do Discurso?}

No cenário brasileiro, Geraldi (2013) situa as especificidades segundo as quais se desenvolveram as relações entre as áreas da Linguística e da Literatura. Trata-se de uma discussão que auxilia na compreensão das abordagens discursivas que investigam as produções literárias. Diferentemente do que aconteceu em vários âmbitos do continente europeu, como na França do apogeu dos métodos estruturalistas ou na antiga União Soviética com suas preocupações formalistas, em que tanto a área da Linguística quanto a área da Teoria da Literatura partilhavam referências, no Brasil não houve essa recepção conjunta. Nomes como Roman Jakobson, Tzvetan Todorov, Julia Kristeva e Roland Barthes ficaram aqui restritos a limites disciplinares. O pesquisador brasileiro sinaliza que essa compartimentalização no cenário brasileiro se conecta à forma pela qual a Linguística foi recebida a princípio nos ambientes acadêmicos, quer dizer,

[...] no Brasil a Linguística foi recebida no campo dos letrados como uma intrusa, tanto que em nossa maior universidade, a Universidade de São Paulo (USP), a cadeira de linguística pertenceu inicialmente ao Departamento de Estudos Orientais. Também o surgimento do Departamento de Linguística na Universidade Estadual de Campinas (UNICAMP) respondia ao projeto cientificista e tecnológico desta universidade, criada para se contrapor à "esquerdizante" e "humanista" USP, tanto que se discutiu nas instâncias universitárias sua localização no Instituto de Matemática e Computação, [...] (GERALDI, 2013, não p.). 
Compreendemos que esse acolhimento da Linguística no Brasil representa um projeto ainda vivo de separação apriorística entre o que diz respeito à língua e o que diz respeito à produção artística. Um dos primeiros estudiosos a se debruçar sobre essa questão, abordando a opacidade da língua, em todas as suas manifestações, foi Volóchinov (2013 [1926]). É a situação social que delineia o discurso verbal, independentemente de estar inserido na vida cotidiana ou na arte. Em se tratando de arte, não podemos estudá-la “[...] como se 'por sua natureza' fosse tão alheia ao sociológico como é a estrutura física ou química de um corpo" (VOLÓCHINOV, 2013 [1926], p. 72). Sua crítica se volta para dois pontos de vista "falsos" que dão acesso ao estudo da arte: a obra de arte enquanto um objeto autônomo e a proeminência da psique do criador ou do bem- estar do contemplador. Nesse sentido,

[...] os dois pontos de vista pecam em um mesmo erro: tentam encontrar uma parte na totalidade; fazem passar a estrutura de uma parte separada do todo pela estrutura da totalidade. Enquanto o "artístico" em sua completude não se encontra no objeto, nem na psique isolada do criador ou do ouvinte, a não ser que abarque os três aspectos por vez. O artístico representa uma forma especial da inter-relação do criador com os ouvintes, relação fixada em uma obra de arte (VOLÓCHINOV, 2013 [1926], p. 75-76).

Sua contribuição evidencia a importância do estudo sociológico, a fim de acessarmos os produtos da criação humana. Propomos, com base nisso, que um estudo discursivo pode contemplar essa totalidade. Ao apresentar algumas abordagens linguístico-discursivas dos textos literários, algumas advindas da Linguística Tex- 
tual, outras da Argumentação ou da Análise do Discurso, Paveau (2013) apresenta, sob o rótulo de Análise do Discurso Literário, a produção de Maingueneau (2016). Em sua visão, o autor “[...] postula que os elementos necessários à leitura de um texto não estão simplesmente no texto [...], mas residem igualmente nos seus contextos, em uma perspectiva onde a oposição binária interno versus externo desaparece" (PAVEAU, 2013, p. 50). A noção de paratopia possibilita a operacionalização dessa abordagem da enunciação literária, na medida em que abrange dois níveis complementares.

De fato, na perspectiva enunciativo-discursiva da Análise do Discurso, desenvolvida por Maingueneau (1996, 2001, 2010, 2015, 2016), estudar o discurso literário significa contrariar duas perspectivas prevalecentes entre os especialistas da Literatura: a análise de textos literários não se faz mais eficaz com a separação entre textos considerados "profanos" e textos considerados "sagrados", deve-se explorar todas as dimensões do universo discursivo; e o recurso aos pressupostos da Linguística não pode ser superficial, é necessário constituir uma rede investigativa que produz interpretações que escapam à mera intuição.

A fim de assumir o fato literário como discurso, é imprescindível "renunciar ao fantasma da obra em si" (MAINGUENEAU, 2016, p. 43, grifo do autor). Essa renúncia implica a desconstrução da autonomia da obra em relação ao seu contexto de produção e da figura de uma consciência criadora que isolada dá corpo à sua genialidade; significa "[...] restituir as obras aos espaços que as tornam possíveis, onde elas são produzidas, avaliadas, administradas" (MAINGUENEAU, 2016, p. 43). A instituição literária não está desligada das configurações enunciativas. Em vez de expressar uma interioridade, uma intenção, o discurso é a construção progressiva de uma identidade enunciativa e de uma legitimação do seu lugar enunciativo, por meio dos quais se pode vislumbrar um posicionamento. Nesse esforço, seria contraditório, portanto, 
[...] dissociar as operações enunciativas por meio das quais se institui o discurso - que constrói dessa maneira a legitimidade de seu posicionamento - do modo de organização institucional que esse discurso a um só tempo pressupõe e estrutura (MAINGUENEAU, 2016, p. 62).

A produção discursivo-literária ganha uma dimensão na qual o movimento de legitimação efetuado pelo discurso se vincula à imagem do enunciador e à forma segundo a qual ele defende seu direito à enunciação. Ainda assim, é preciso admitir que o objeto "discurso literário" é recoberto por uma grande instabilidade. Ao passo que diz respeito a um tipo de discurso socialmente identificável e com estatuto pragmático definido, pode indicar agrupamentos de discursos produzidos em configurações sociais e períodos históricos muito distintos entre si.

Ademais, uma compreensão discursiva da produção literária permite o questionamento da própria concepção tradicional dessa arte, em geral, alicerçada em ritos excludentes de linguagem definidos por grupos pequenos. Com efeito, o discurso literário deixa de ser compreendido como "[...] um suplemento, um 'ornamento' que se soma a uma língua, que está por natureza voltada a tarefas de comunicação mais elementares" (MAINGUENEAU, 2016, p. 197). A comodidade desta concepção mascara sua insuficiência, uma vez que os discursos literários participam da própria constituição da língua, conferindo-lhe o estatuto de língua.

Com base no reconhecimento da instabilidade do objeto "discurso literário", podemos nos ocupar das especificidades da enunciação literária. Devido a certos pontos de convergência, realizamos essa tarefa por meio de um diálogo com Deleuze $(1992,1997)$ e Machado (2009), que sistematiza as reflexões deleuzianas sobre 
as artes, inclusive a literária. Defendemos que são pelo menos três os pontos de convergência entre uma abordagem discursiva e o pensamento deleuziano quanto à enunciação literária.

O “poder de desestabilização" (MAINGUENEAU, 1996, p. 30) é um desses pontos. No pensamento deleuziano, ele surge como um dos aspectos centrais da enunciação literária, cujo "valor [...] diz respeito ao novo, ao inesperado, à mutação, à invenção" (MACHADO, 2009, p. 206). Ora, a/o escritor/a produz em um campo literário que historicamente estabelece atitudes ditas de escritor/a, no entanto, espera-se sempre que a/o produtor/a desse tipo de discurso perturbe esses condicionamentos cada vez que enuncia. Além disso, a desestabilização aparece também quando o criador introduz linhas de fuga na variedade padrão da língua, fazendo-a escapar, em um estado de variação contínua, do regime vigente, dominante. Essa reviravolta que a enunciação literária produz na norma-padrão permite que a linguagem se distancie da representação e adquira a potência de dizer o que é indizível para os modos de enunciação não literários (MACHADO, 2009).

O outro ponto concerne à transitividade da enunciação literária. A desestabilização que cada produtor/a do discurso literário negocia tensiona todas as outras formas de enunciação, direcionando-as para um "de-fora", para a fuga do senso comum, o que pode motivar novas formas de existência, novas comunidades. Quer dizer,

O procedimento [literário] impele a linguagem a um limite, mas nem por isso o transpõe. Ele devasta as designações, as significações, as traduções, mas para que a linguagem afronte enfim, do outro lado de seu limite, as figuras de uma vida desconhecida e de um saber esoté- 
rico. O procedimento é apenas a condição, por mais indispensável que seja. Chega às novas figuras quem sabe transpor o limite (DELEUZE, 1997, p. 30, grifos nossos).

Nesse excerto, Deleuze (1997) aborda a relação entre o literário e o limite, habitado pelas possibilidades de uma vida desconhecida e de um outro saber. Em Maingueneau (1996, 2001, 2010, 2015, 2016), identificamos um movimento similar na noção de discurso constituinte e no seu caráter paradoxal, a paratopia. A perspectiva do analista do discurso não deixa de indicar esse processo de criação de lugares, de comunidades no mundo por meio do discurso literário. A/o escritor/a se aproveita de seu pertencimento problemático à sociedade para inventar, nos termos do filósofo, "um povo que falta" (DELEUZE, 1997, p. 14).

Sem deixar de ter em vista a complementariedade dos pontos indicados, destacamos, por fim, a resistência à dominação presente na enunciação literária. O trabalho literário “[...] invoca essa raça bastarda oprimida [as/os escritoras/es] que não para de agitar-se sob as dominações, [que não para] de resistir a tudo o que esmaga e aprisiona e [que não para] de, como processo, abrir um sulco para si na literatura" (DELEUZE, 1997, p. 15). Neste ponto, a condição da/o escritor/a a/o coloca em uma posição de revolucionária/o, de insurgente, o que, conforme discutiremos na seção seguinte, enlaça a sua produção à sua vida e vice-versa. Por meio de uma configuração singular da enunciação literária, "pode-se instaurar uma zona de vizinhança com não importa o quê" (DELEUZE, 1997, p. 11), uma zona que burla a ordem estabelecida, as significações dominantes. Maingueneau $(2001,2015)$ nos lembra que, justamente por este motivo, as tentativas de controle dos artistas pelo governo, com o objetivo de torná-los funcionários inseridos em uma burocracia, acabam resultando na perda da arte de sua razão de ser 
e, consequentemente, surgem maneiras alternativas, resistentes ao controle governamental e que se designam autênticas.

Com esta seção, nosso objetivo é demarcar os traços da enunciação literária que a diferenciam de outros tipos de enunciação; em outras palavras, evidenciar que sua desestabilização, sua condição limítrofe, que aponta para outras existências possíveis, e sua resistência à dominação ocasionam desdobramentos discursivos que serão discutidos na próxima seção. Esse movimento também ajuda a distanciar a nossa pesquisa de uma concepção recorrente do trabalho literário, associada às belas-letras, à eloquência, ao apego aos ritos já consagrados.

\section{A paratopia da/o escritor/a e o gerenciamento de sua imagem}

Começamos esta seção abordando a noção de imagem de autor/a, com a finalidade de realçar sua importância para uma abordagem discursiva da enunciação literária e de discernir as instâncias enunciativas envolvidas nesse processo. Em um segundo momento, tratamos da paratopia da/o escritor/a. Dado o seu estatuto de condição e produto do discurso literário, esta noção é favorecida em uma análise à qual se incorpora o estudo da imagem de autor/a, um fenômeno que ultrapassa os limites enunciativos e ocorre na interação entre autor/a, público e texto (MAINGUENEAU, 2010).

Maingueneau (2010) sustenta que a noção de imagem de autor/a apresenta duas faces diferentes em consequência da sua natureza de seu gerenciamento. De forma concomitante, a imagem é elaborada por intervenientes externos e pela/o própria/o escri- 
tor/a, em um processo no qual o gerenciamento de sua imagem acaba se confundindo com a sua trajetória na atividade literária. Nesta pesquisa, ainda que dados biográficos sejam apresentados, sobressai a face regulada pela escritora, quer dizer, que advém de produções que, de formas diferentes, contam com a sua chancela. Não há como negar, de qualquer forma, que a imagem de autor/a, sujeito responsável por um opus reverenciado no campo, é "elaborada na confluência de seus gestos e de suas palavras, de um lado, e das palavras dos diversos públicos que, a títulos diferentes e em função de seus interesses, contribuem para moldá-la” (MAINGUENEAU, 2010, p. 144).

O valor dessa noção para uma abordagem discursiva da enunciação literária é justificável, pois ela envolve os três polos da enunciação literária e, dessa maneira, não pode ser desconsiderada. No polo de produção, a/o criador/a ajusta sua trajetória em função da imagem que não cessa de construir para si em seu campo de atividade; no polo do texto, a formatação, as escolhas editoriais e a circulação dos textos são desenvolvidas mediante uma imagem de autor/a; e, no polo da recepção, a imagem de autor/a condiciona as estratégias de leitura-consumo, bem como, antes disso, a decisão de aderir a uma relação com determinado discurso literário, em um processo que sofre, de modo contínuo, a interferência dessa imagem (MAINGUENEAU, 2010).

A reflexão sobre a imagem de autor/a é possível, em consonância com Maingueneau (2010), devido à influência de correntes pragmáticas e discursivas que trazem outras perguntas para a análise do fato literário. Algumas delas se direcionam para a complexidade dos processos de subjetivação atuantes na enunciação literária. Ao confrontar os trabalhos de Maingueneau (2010, 2016), distinguimos três instâncias que nos auxiliam no reconhecimento dessa complexidade. Quanto a essa problemática, segmentos do 
livro Discurso literário ${ }^{44}$ contestam a divisão tradicional da/o escritor/a em duas figuras, uma criadora de uma obra e outra que existe socialmente, ao passo que apresentam a distinção de três instâncias: a pessoa, o escritor e o inscritor. Nessa proposição,

A denominação "a pessoa" refere-se ao indivíduo dotado de um estado civil, de uma vida privada. "O escritor" designa o ator que define uma trajetória na instituição literária. Quanto ao neologismo "inscritor", ele subsume ao mesmo tempo as formas de subjetividade enunciativa da cena de fala implicada pelo texto (aquilo que vamos chamar [...] de "cenografia") e a cena imposta pelo gênero do discurso [...] O "inscritor" é, com efeito, tanto enunciador de um texto específico como, queira ou não, o ministro da instituição literária, que confere sentido aos contratos implicados pelas cenas genéricas e que delas se faz o garante (MAINGUENEAU, 2016, p. 136).

Em um trabalho posterior, Maingueneau (2010) modifica essa divisão em particular quanto à instância do inscritor que passa, então, a integrar "duas funções de níveis distintos: a de enunciador, isto é, suporte da enunciação, e a de agenciador do texto (que se manifesta em particular através de seu recorte, de sua apresentação)” (MAINGUENEAU, 2010, p. 143, grifos do autor). A função de garante, que valida os contratos das cenas genéricas, é retirada da instância do inscritor e ganha estatuto próprio. O autor-responsável ou autor-garante é a instância que assume a responsabilidade por um discurso. Logo, não é exclusiva da enunciação literária. Essa instância é negociada por meio do título, da epígrafe, da capa

44 Cf. Maingueneau (2016). A primeira edição do livro foi publicada na França em 2004. 
etc.; dela emerge um ethos discursivo que contribui para a composição de uma imagem de autor/a.

Além do autor-responsável ou autor-garante, cuja existência se dá em torno de elementos textuais e paratextuais, há outros fatores nesse entorno que contribuem para a construção da imagem de autor/a. Para Maingueneau (2010), são eles: as personagens, que podem contaminar sua imagem; os gêneros, na medida em que nos deixam vislumbrar uma certa relação com a instituição literária; as cenografias, das quais sobressaem ethé discursivos, topografias e cronografias; o nome da/o autor/a, quando seu posicionamento e sua trajetória no campo já são estimados; e, finalmente, o ethos editorial, vinculado à organização de coleções, à escolha de materiais, como o tipo de papel, e à diagramação.

A instância do escritor ou do autor-ator, de acordo com o termo empregado em Maingueneau (2010), é aquela que coordena uma trajetória, uma carreira na instituição literária. Ator da cena literária, deve administrar o enlace entre a sua produção literária e sua encenação, em um movimento no qual esta traduz aquela e vice-versa. Em outros termos, "a encenação do escritor não é apreendida [...] como um conjunto das atividades que permaneceriam fora do recinto sagrado do Texto, mas como uma dimensão constitutiva do discurso literário" (MAINGUENEAU, 2010 p. 141). Uma vez que nossa pesquisa se localiza nesse espaço em que aspectos da vida privada são encenados com objetivos particulares, averiguar a instância da pessoa, de forma que é descrita em Maingueneau (2016), parece-nos dispensável.

Se todo discurso tem um autor-garante, poucos são aqueles que usufruem da figura de um auctor, que está relacionado a uma obra, uma produção estimada e identificável em um campo discursivo. Podemos dizer que essa dispersão das instâncias enuncia- 
tivas descrita até aqui é atraída pela unidade imaginária que é a figura de um auctor (MAINGUENEAU, 2016) ${ }^{45}$. Para ascender a este degrau, é imprescindível a intervenção de terceiros que assim o declaram e organizam uma produção sobre sua obra e sua figura, contribuindo para a construção de uma imagem de autor/a (MAINGUENEAU, 2010).

Esse processo, conforme Maingueneau (2010), constitui-se em duas zonas principais das quais são produzidos sinais que modelam a imagem de autor/a: uma em torno do texto; e a outra em torno do autor-ator, cujo posicionamento no campo literário pode ser revelado por meio de sua maneira de explorar e de interferir nos comportamentos condicionados pela instituição literária. $\mathrm{O}$ autor-ator, por sua vez, dedica-se a um trabalho duplo, de "regulação" e de "figuração".

A "regulação" torna possível reorientar a trajetória de conjunto em que se situa toda a obra singular: ser escritor é assim dar sentido a suas atividades passadas e presentes em função de um futuro projetado. Isso passa por gêneros muito diversos: entrevistas concedidas a jornalistas, manifestos, debates, escritos sobre outras artes, prefácios de obras de outros escritores, obras sobre outros escritores... Associa-se a essa "regulação" um trabalho de "figuração" por meio do qual o ator se põe de algum modo em cena como escritor: viaja ou não, vive afastado no campo ou no centro de uma cidade grande, aparece na televisão ou oculta o rosto etc. (MAINGUENEAU, 2010, p. 147).

45 Em Maingueneau (2016), é utilizado o termo “Autor”, com maiúscula. 
Essas duas vias de trabalho compõem a encenação de uma singularidade produtora que legitima um posicionamento no campo literário. Apesar de não existirem fronteiras exatas entre essas duas vias, elas nos auxiliam a dar conta dessas relações. Enquanto a "regulação" pode servir para colocar certas criações em perspectiva, relacionando-as a um opus, a dimensão da "figuração" colabora na negociação de uma identidade criadora em cena.

Em Maingueneau (2016), essas dimensões da atuação da/o autor/a podem se dar em dois espaços indissociáveis: um espaço canônico e um espaço associado. A despeito do termo, o espaço associado não é um apêndice do espaço canônico; na verdade, ambos se alimentam um do outro. $\mathrm{O}$ espaço canônico, com efeito, é o mais evidente, posto que nele a/o autor/a assume de forma mais explícita a sua criação. Já no espaço associado, a/o autor/a se distancia dos mundos que constrói, em geral, comentando-os ou comentando as obras de outras/os autoras/es. No corpus que analisamos, assumimos que a entrevista se situa no espaço associado do discurso hilstiano e a produção cronística, no espaço canônico. Como veremos na próxima seção, esses dois espaços remetem um ao outro e cooperam com a elaboração de uma imagem da autora.

O conceito de discurso literário, conforme o que foi assinalado até aqui, sobrepõe questões linguísticas e sociais e, dessa forma, é concebido como “[...] força de consolidação, vetor de um posicionamento, construção progressiva, através do intertexto, de certa identidade enunciativa e de um movimento de legitimação do espaço próprio de sua enunciação" (MAINGUENEAU, 2016, p. 43). Não é possível fechá-lo em uma interioridade. Sua construção progressiva é impactada por aspectos biográficos da/o autor/a, ou melhor, por sua encenação. Em especial no caso de um auctor, seu modo de vida não se separa completamente de sua produção literária. Cada auctor introduz singularidades na maneira de ge- 
rir sua condição de produtor/a de um discurso constituinte e, em uma abordagem discursiva, seu comportamento não pode ser desconsiderado, pois participa contínua e efetivamente da criação. $\mathrm{O}$ pensamento deleuziano se orienta nesta mesma direção, segundo a qual "o estilo, num grande escritor, é sempre também um estilo de vida, de nenhum modo algo pessoal, mas a invenção de uma possibilidade de vida, de um modo de existência" (DELEUZE, 1992, p. 126). Maingueneau (2001) emprega, inclusive, bio/grafia, com uma barra que ao mesmo tempo une e separa os dois itens, para designar a união entre aspectos biográficos e as produções discursivas da/o escritor/a. Para o analista, tal bio/grafia "[...] se percorre nos dois sentidos: da vida rumo à grafia ou da grafia rumo à vida" (MAINGUENEAU, 2001, p. 46, grifos do autor).

Cada produtor/a de discurso constituinte precisa administrar uma identidade condizente com as formas de pertencimento e não pertencimento típicas desse tipo de discurso. Quem produz um discurso constituinte "[...] não pode situar-se no exterior nem no interior da sociedade: está fadado a dotar sua obra do caráter radicalmente problemático de seu próprio pertencimento a essa sociedade" (MAINGUENEAU, 2016, p. 68). Nessa perspectiva, não se deve atrelar, de forma instantânea, modos de existência social à paratopia. Para que haja paratopia, um processo criador deve ser desenvolvido. De acordo com Maingueneau (2016), a/o escritor/a não tem lugar e propósito determinados, logo, na qualidade de produtor/a de um dos discursos constituintes, precisa construir um território para si por meio dessa falha.

A paratopia, assim, diz respeito à condição problemática de cada produtor/a de discurso literário em relação à sociedade, bem como ao espaço discursivo que gerencia. Condição e produto da enunciação literária, a paratopia negocia a existência de um determinado discurso e de uma imagem de autor/a que a legitima e é 
por ela legitimada. Por isso, a gestão da paratopia, no nível de cada escritor/a, é parte constitutiva do discurso literário, cuja produção depende e se alimenta da impossibilidade de se estabilizar.

Associada ao nível de cada produtor/a, a paratopia também pode ser identificada no nível de cada discurso constituinte, cada agrupamento discursivo definido mediante o seu "pertencimento" à sociedade; que, ao mesmo tempo, pertence e não pertence a ela e, por isso, busca legitimar-se a si próprio. Esse traço é incorporado a várias dimensões discursivas, sendo negociado, a princípio, em uma cenografia que faz do discurso um lugar de representação de sua própria enunciação, na emergência de um ethos discursivo que dá uma voz ao discurso, ativando o imaginário estereotípico de um corpo enunciante socialmente avaliado, e no investimento em um código linguageiro que opera sobre a diversidade de zonas e registros de língua.

Por intermédio da paratopia é que se dá o discurso de um auctor e, ao mesmo tempo, no desenvolvimento do seu conjunto discursivo se constrói a sua paratopia. Devido ao lugar social incongruente de sua/seu produtor/a e à posição que ocupa no universo discursivo, o discurso literário "[...] não pode dissociar seus conteúdos da legitimação do gesto que os propõe; a obra só pode configurar um mundo se este for dilacerado pela remissão ao espaço que torna possível sua própria enunciação" (MAINGUENEAU, 2016, p. 119). A/o escritor/a precisa transformar em discurso sua errância, fazendo emergir nele, portanto, as mais variadas representações da paratopia.

Em seus dois níveis, esse pertencimento paradoxal não é origem ou causa, menos ainda uma condição que preexiste a um agrupamento discursivo que somente a expressa. Cabe às/aos criadoras/es organizar seus discursos em torno das tensões para- 
doxais, que se mostram paratópicas no desenvolvimento de suas cenas de enunciação.

\title{
A condição da obscena senhora $H$.: provocação $e$ comicidade
}

\author{
“[...] no fundo sempre desejei me comunicar com \\ muita intensidade [...]"
}

Hilda Hilst (1989) ${ }^{46}$

Logo depois de lançar a tetralogia obscena, Hilda Hilst passa a produzir crônicas semanalmente para o "Caderno C" do Correio Popular da cidade de Campinas, o jornal local de maior circulação. Essa produção se estende de 1992 a 1995 e é publicada em forma de coletânea pela primeira vez em 1998 com o título Cascos \& carícias. No mesmo jornal, anos antes, em 1989, a autora discutia em uma entrevista concedida a Marici Salomão mudanças na trajetória do seu trabalho literário. Para promover uma análise conjunta da paratopia da escritora e do gerenciamento da imagem da autora, dividimos esta seção em duas partes que são dedicadas, cada uma, a um dos gêneros que compõem nosso corpus.

Seguindo a cronologia, abordamos, em primeiro lugar, a entrevista concedida a Marici Salomão. Nesse segmento da análise, buscamos traços que apontam para uma imagem prévia da autora, fabricada na confluência das instâncias autor, texto e público.

46 Trecho da entrevista concedida a Marici Salomão e veiculada no jornal Correio Popular. 
Recuperamos, por isso, dados biográficos em certos momentos, uma vez que sua encenação é veiculada para o público e recuperada, muitas vezes, no trabalho de "regulação" do autor-ator. Selecionamos esta entrevista, pois entendemos que representa um dos exemplares iniciais e mais explícitos do reposicionamento da autora no campo literário, iniciando uma reorientação de sua imagem no espaço associado que, aos poucos, difunde-se pelo espaço canônico. Isso fica evidente, por exemplo, no título da entrevista: "Amavisse, o último livro sério da autora Hilda Hilst".

Recorreremos também a trechos da parte introdutória da entrevista, a fim de situarmos, de forma sucinta, a intervenção de terceiros na construção da imagem da autora. Esse segmento atualiza temas centrais envolvidos na construção e na manutenção da imagem da autora. As/os produtoras/es do discurso constituinte surgem em sua "lúcida loucura [...] [pois] sabem retirar o véu das aparências para penetrar no árduo caminho dos valores essenciais" (SALOMÃO apud HILST, 1989, p. 29). A essa caracterização das/ os produtoras/es, é acrescentada outra dimensão, a da escritora hermética: "mas Hilda já não guarda ilusões quanto à receptividade de seu trabalho: sempre foi rotulada como escritora hermética, de difícil compreensão" (SALOMÃO apud HILST, 1989, p. 29). Questão premente para a figura da/o escritor/a, a receptividade, no caso da Hilda, é recuperada diversas vezes ao longo de sua trajetória e, no exemplar em questão, aparece nas respostas da própria autora. Uma das grandes decepções da autora havia acontecido em 1982, quando a publicação do livro A obscena senhora $D$. não repercutiu no campo literário como se esperava (CECILIO, 2018).

O espaço no qual a autora vive e produz é outro desses temas recorrentes atualizados. Durante a entrevista, Hilda se encontra na "espaçosa e intimista Casa do Sol [...], rodeada de seus doze cachorros vira-latas e em meio à fumaça de cigarros e muitos livros" 
(SALOMÃO apud HILST, 1989, p. 29). Aos 36 anos, cansada dos eventos sociais e influenciada pela leitura do livro confessional Testamento para El Greco, de Nikos Kazantzákis, muda-se para a área rural. Nesse livro, "a vivência plena da criação literária exige o afastamento do mundo, porque a literatura deve ser sagrada" (CECILIO, 2018, não p.). Lá instala a Casa do Sol, onde produz e começa a buscar evidências sobrenaturais por meio de experimentos que são apresentados ao público pela mídia, inclusive pelo programa Fantástico, em 1979. Ressaltamos dois aspectos sobre esse tema. O comportamento da autora integra, dada influência do livro de Kazantzákis, um rito tradicional para a figura da/o escritor/a, o afastamento espacial. Isso nos conduz a outro aspecto: nesse espaço de encenação do autor-ator, a paratopia no nível da/o produtor/a, além de conservar uma representação espacial, é maximizada pela mediunidade, cuja figura transita por mundos diferentes.

A partir do momento em que a voz da escritora aparece na entrevista, são discutidos os motivos da mudança na sua trajetória, que pode ser entendida, pelo menos a princípio, como uma reação à percepção da dificuldade de viver de poesia e ao silêncio prolongado da crítica e do público (CECILIO, 2018). No percurso,

Chegou uma determinada hora que comecei a ver que tinha trabalhado quarenta anos - eu comecei a escrever com dezoito, publiquei meu primeiro livro aos vinte - e vi que realmente não tinha dado certo. Todo homem de alguma forma quer ter alguma importância. Isso significa ter mais vida, porque isso dá perdurabilidade... (HILST, 1989, p. 29).

Ao tratar da busca pelo público, Hilda indica que há duas formas de lidar com seu silêncio. A santidade ou o riso seriam esses 
“caminhos de salvação" (HILST, 1989, p. 29). Sua recusa ao primeiro é realizada por intermédio da comicidade, qualidade sintomática de um reposicionamento no campo literário que também reorienta a negociação de sua imagem: "o outro caminho é a santidade, mas já está tarde demais para se entregar o bagaço a Deus" (HILST, 1989, p. 29). Depois de 40 anos de dedicação à atividade literária, escolhe o riso como uma forma de salvação: “[...] o riso, apesar de parecer patético, [...] é um dos caminhos de salvação" (HILST, 1989, p. 29).

Paradoxalmente, como é investigado a seguir, a opção por essa forma de salvação incrementa as representações da paratopia no discurso hilstiano. Em vez de procurarmos causas para a mudança em sua trajetória, concebemo-la como uma encenação que aprofunda a paratopia da escritora. A comicidade, a provocação persistente e a obscenidade são elementos incorporados à sua produção, porque "para criar, deve-se sobretudo não encontrar um lugar, agudizar a paratopia” (MAINGUENEAU, 2016, p. 138).

Examinamos, em segundo lugar, três discursos que compõem a coletânea 132 crônicas: cascos \& carícias e outros escritos. São eles: "Por quê, hein?", “Tamo numa boa!” e "'Esqueceram de mim' ou 'tô voltando"'. Desses discursos, destacamos três dimensões afetadas pela paratopia: a cenografia, o ethos discursivo e o código linguageiro. A cenografia é um dispositivo que associa o discurso às condições que propiciam sua criação. Não é imposta pelo tipo ou pelo gênero, mas instituída no e pelo próprio discurso, e é com ela que o co-enunciador lida diretamente. A cenografia legitima e é legitimada pelo discurso, confundindo-se com o enunciado que sustenta, e o enunciado, por sua vez, também sustenta a cenografia. O processo cenográfico é central, para mostrar que o enunciador negociou um código linguageiro adequado àquele universo e para 
constituir e legitimar o ethos discursivo (MAINGUENEAU, 2016).

Nesses discursos, desenvolve-se uma cenografia interpelativa segmentada, que se desdobra em confrontar de forma provocativa seu co-enunciador e em questioná-lo sobre aquele momento sócio-histórico e cultural, o início da década de 1990. Em "Por quê, hein?", o enunciador pergunta:

O que eu escrevo nestas crônicas lhes parece incompreensível e nojento? Os buracos negros também são incompreensíveis e nojentos, pois engolem tudo [...], e todo mundo agora fala deles. Essa modesta articulista que sou eu escreveu textos e poemas belíssimos e compreensíveis, e tão poucos leram ou compraram meus livros... Mas agora com essas crônicas... que diferença! Como telefonam indignados [...], dizendo que sou nojenta! Obrigada, leitor; por me fazer sentir mais viva e ainda por cima nojenta! (HILST, 2018, p. 25-26).

Essa cenografia é sustentada por um ethos discursivo comprometido com a provocação, sobretudo à associada à figura da/o escritor/a que desestabiliza a ordem dominante, que desafia as regras sociais: "Quem sabe se consigo ativar vossas serotoninas com esta croniqueta primorosa, feita especialmente para incitar-vos à cólera, às espuminhas-esquizo no canto da boca, à gritaria, óóóóóhhhh, lá vem ela outra vez, a odiosa! Vamos lá!” (HILST, 2018, p. 199). O ethos discursivo é uma noção sociodiscursiva que se constrói por meio do discurso em um processo interativo de influência sobre o co-enunciador (MAINGUENEAU, 2016). Em outros termos, concerne a um comportamento socialmente avaliado, que é compreendido dentro de uma situação específica de comunicação e de 
uma conjuntura sócio-histórica determinada. O co-enunciador, por meio de indícios textual-discursivos, discerne um conjunto de traços físicos e psíquicos que se sustentam em representações sociais valorizadas ou desvalorizadas, em estereótipos culturais, que podem ser reforçados ou transformados.

O código linguageiro empregado ratifica as conclusões de Candido (1992) sobre o gênero crônica, cuja capacidade de restabelecer a dimensão das coisas depende de uma linguagem que aproxima enunciador e co-enunciador. Destacam-se a recorrência de itens lexicais aspeados, o prolongamento de itens lexicais, em uma tentativa de se aproximar da modalidade falada, e comentários entre parênteses, como em “[...] (informe-se) [...]” (HILST, 2018, p. 199). O código linguageiro, uma configuração específica que determinada formação discursiva emprega no momento da enunciação, convoca outra língua na língua. Em outras palavras, a/o produtor/a, como argumenta Deleuze (1997), introduz linhas de fuga na norma-padrão, colocando-a, em um estado de variação. O uso que se faz da língua participa da autolegitimação do enunciador. Então, a/o produtor/a do discurso literário deve negociar um código linguageiro que lhe é característico, relacionando-o à sua paratopia e à sua imagem.

A posição do enunciador, produtor de discurso literário, mostra-se como condição de enunciação. Coloca-se em questão, portanto, a figura de um sujeito que divulga sua produção anterior e discute a pouca receptividade do público a ela. Seu tom insurgente ao discuti-la manifesta, por um lado, uma busca pela legitimação de sua posição, posto que o "escritor como vidente e ouvidor" (DELEUZE, 1997, p. 16) não pode ser completamente elucidado; e, por outro, uma estratégia conveniente para conseguir a resposta do co-enunciador: “[...] com essas crônicas... que diferença! Como telefonam indignados [...], dizendo que sou nojenta! Obrigada, leitor; por me fazer sentir mais viva e ainda por cima nojenta!" (HILST, 
2018, p. 25-26). De acordo com Pécora (2015), na época da publicação, essas crônicas dividiram a cidade de Campinas.

Este trecho da crônica "Tamo numa boa!" deve ser realçado pelo o que foi sustentado acima e por outro motivo, apresentado a seguir:

Quando o cu do Liu-Liu olhou o céu pela primeira vez, ficou bobo. Era lindo! E ao mesmo tempo deu uma tristeza! Pensou assim: eu, fiu-fiu, que não sou nada, sou apenas um cu, pensava que era Algo. E nos meus enrugados até me pensava perfumado! E só agora é que eu vejo: quanta beleza! Eu nem sabia que existia borboleta!

Borboleta pra vocês também! Bom dia! (HILST, 1989, p. 166).

Trata-se da reprodução verbatim de um parágrafo do livro $O$ caderno rosa de Lori Lamby, um dos livros em prosa que compõem a tetralogia obscena. O parágrafo encerra a história do sapo Liu-Liu; idealizado pela personagem-escritora Lori, ele "tinha muita pena do seu cu [...] [e faz] de tudo pra que um rainho de Sol entre nele, coitadinho!" (HILST, 2018, p. 165). A autora faz referência a uma produção que havia sido publicada há alguns anos, ao mesmo tempo em que cobra do seu co-enunciador, por intermédio da frase “Borboleta pra vocês também!", uma posição menos conformista, mais aberta a um outro saber.

Embora Queiroz (2000) assegure que a subversão formal e a transgressão temática são aspectos básicos de produção em prosa 
da autora, julgamos que, na tetralogia obscena e na produção cronística, há um aprofundamento da transgressão, pelo acréscimo da obscenidade. Por esse outro motivo que colocamos em evidência acima o trecho do discurso “Tamo numa boa!”. Nesse sentido, suas crônicas não só subvertem a expectativa usual em relação ao gênero, isto é, um comentário otimista sobre as notícias recentes que estabelece uma identificação entre enunciador e co-enunciador, como também sustentam, em suas dimensões discursivas, um enfrentamento ao posicionamento conformista do co-enunciador do início da década de 1990.

A reorientação da imagem da autora, anunciada na entrevista, chega ao espaço canônico com a publicação da tetralogia obscena e, depois, com a veiculação das crônicas no jornal campineiro. Algumas escolhas da autora, como o gênero crônica, a veiculação no jornal de maior circulação na região, o código linguageiro firmado e o emprego da comicidade para discorrer sobre temas menos abstratos, como a velhice e a política nacional, concretizam um deslocamento em sua trajetória. $\mathrm{Na}$ intensificação da paratopia, a/o escritor/a segue um caminho contrário ao da topia, ao pertencimento pleno à sociedade, e vê-se atraída/o por um topia distinta: "a esperança de ocupar uma posição em algum Panteão, em alguma Memória, de ser plenamente reconhecido" (MAINGUENEAU, 2016, p. 138).

\section{Conclusão: outros caminhos de investigação a serem percorridos}

Ao longo deste capítulo, investigamos, de acordo com a perspectiva enunciativo-discursiva da Análise do Discurso de linha francesa, desenvolvida por Maingueneau (1996, 2001, 2010, 2015, 
2016), a noção de paratopia da/o escritor/a no cruzamento de dois gêneros de discurso distintos. Nosso objetivo foi examiná-la de forma concatenada com a reorientação da imagem de autora, cujo gerenciamento é realizado na fronteira entre os espaços canônico e associado.

Os resultados da análise indicam que a gestão da paratopia da escritora busca elucidar o silêncio dos co-enunciadores, inclusive dos autorizados no campo literário, ou seja, da crítica especializada. Na sobreposição dos espaços canônico e associado, um tom insurgente se agrega à imagem de autora afastada dos espaços tópicos da sociedade. O efeito desse deslocamento é reforçado pela escolha da comicidade, sintomática de um reposicionamento no campo literário, e pela exploração de uma cenografia interpelativa segmentada que sustenta um enfrentamento ao posicionamento conformista do co-enunciador do início da década de 1990. Não defendemos que há uma ruptura da imagem prévia da autora; há, antes, sua reorientação aliada ao aprofundamento das representações da paratopia na sua produção.

É lídimo evidenciar, enfim, a natureza introdutória deste estudo. Julgamos que sua ampliação deva se dar em pelo menos quatro sentidos: 1) é necessário explorar o conflito no campo literário, detalhando o posicionamento da autora em oposição a outro/s posicionamento/s, sobretudo o conformista do início da década de 1990; 2) em relação à sua produção cronística, surgem perguntas sobre o papel desempenhado por essa mudança de $m i$ dium que devem ser respondidas; 3) a intervenção de terceiros na construção da imagem da autora precisa ser investigada, tanto no período em que estava viva, quanto no período póstumo, já que esses dois modos interagem, permitindo reposicionamentos dos discursos literários (MAINGUENEAU, 2010); 4) e a configuração sócio-histórica e cultural da obscenidade e o seu lugar na constru- 
ção de um posicionamento no campo literário devem ser analisados em detalhe.

Além desses caminhos, devemos dar importância, a julgar pelas configurações mais recentes que a produção discursivo-literária assume, aos livros eletrônicos e aos blogs e vlogs literários. As modificações do acesso e da circulação manifestam outras possibilidades de criação e de leitura-consumo. Essas paisagens midiológicas recentes demandam estudos que se aventurem pelos seus efeitos, para compreendermos mais a fundo o discurso literário produzido nesse momento histórico e sua nova configuração paratópica.

\section{Referências}

CANDIDO, Antonio. A vida ao rés-do-chão. In: CANDIDO, Antonio et al. A crônica: o gênero, sua fixação e suas transformações no Brasil. Campinas, SP: UNICAMP, 1992. p. 13-22.

CECILIO, Ana Lima. A obscena senhora H. In: HILST, Hilda; ABREU, Caio Fernando; CECILIO, Ana Lima. Três vezes Hilda: biografia, correspondência e poesia. São Paulo: Companhia das Letras, 2018. E-book. Não p.

DELEUZE, Gilles. A vida como obra de arte. In: DELEUZE, Gilles. Conversações 1972-1990. Trad. Peter Pál Pelbart. São Paulo: Ed. 34, 1992. p. 118-126.

DELEUZE, Gilles. Crítica e clínica. Trad. Peter Pál Pelbart. São Paulo: Ed. 34, 1997.

HILST, Hilda. Amavisse, o último livro sério da autora Hilda Hilst. Entrevista concedida a Marici Salomão. Correio Popular, Campinas, SP, 7 maio 1989. Arte e Variedades, p. 29. 
HILST, Hilda. 132 crônicas: cascos \& carícias e outros escritos. 1. ed. Rio de Janeiro: Nova Fronteira, 2018. (Coleção Clássicos de Ouro).

GERALDI, João Wanderley. Literatura e Linguística: outros campos, outros saberes. Línguas \& Letras, Cascavel, PR, v. 14, n. 27, não p., 2013.

MACHADO, Roberto. A linguagem literária e o de-fora. In: MACHADO, Roberto. Deleuze, a arte e a filosofia. Rio de Janeiro: J. Zahar, 2009. (Coleção Estéticas). p. 206-221.

MAINGUENEAU, Dominique. Pragmática para o discurso literário. Trad. Marina Appenzeller. São Paulo: Martins Fontes, 1996.

MAINGUENEAU, Dominique. O contexto da obra literária: enunciação, escritor, sociedade. Trad. Marina Appenzeller. 2. ed. São Paulo: Martins Fontes, 2001. (Coleção Leitura e Crítica).

MAINGUENEAU, Dominique. Doze conceitos em análise do discurso. (org.) Sírio Possenti e Maria Cecília Pérez de Sousa-e-Silva. São Paulo: Parábola, 2010.

MAINGUENEAU, Dominique. Discurso e análise do discurso. Trad. Sírio Possenti. São Paulo: Parábola, 2015.

MAINGUENEAU, Dominique. Discurso literário. Trad. Adail Sobral. 2. ed. São Paulo: Contexto, 2016.

NASCIMENTO, Jarbas Vargas et al. A parábola do filho pródigo. São Paulo: LPB, 2009.

PAVEAU, Marie-Anne. A análise linguística de textos literários: uma falsa evidência. Trad. Ismael Ferreira Rosa. Linguagem: estudos e pesquisas, Catalão, GO, v. 17, n. 2, p. 43-59, jul./dez. 2013.

PÉCORA, Alcir. Hilda menor: teatro e crônica. In: REGUERA, Nilze Maria Azeredo; BUSATO, Susanna (org.). Em torno de Hilda Hilst. 1. ed. São Paulo: Unesp Digital, 2015. p. 13-27. 
QUEIROZ, Vera. Hilda Hilst: três leituras. Florianópolis: Mulheres, 2000.

VOLÓCHINOV, Valentin N. A palavra na vida e a palavra na poesia: introdução ao problema da poética sociológica. In: VOLÓCHINOV, Valentin N. A construção da enunciação e outros ensaios. org. e trad. João Wanderley Geraldi. São Carlos, SP: Pedro \& João Editores, 2013. p. 71-100. 